\title{
Values of Character Education in Their Learning Era
}

\author{
Salmah Naelofaria ${ }^{1}$, Izuddinsyah Siregar ${ }^{2}$ \\ Universitas Negeri Medan ${ }^{1}$ \\ Politeknik Negeri Medan² \\ snaelofaria@gmail.com¹, izzuregar@gmail.com²
}

\section{Article History}

accepted 1/09/2020

approved 4/10/2020

published 1/12/2020

\begin{abstract}
Freedom of learning is an educational policy that was initiated in 2019. Free education is inseparable from the bonds of character values. Even though the policy of independent learning was able to produce several new regulations in the world of education, the implementation of character values as a form of virtuous human resources cannot be eliminated. The implementation of these character values can be applied in the process of teaching and learning activities in schools. The character values that are applied in independent learning include: (1) having faith, being devoted to God Almighty, and having a noble character, (2) global diversity, (3) mutual cooperation, (4) independent, (5) critical reasoning, (6) creative. All of these values can be applied in teaching and learning activities in schools.
\end{abstract}

Keywords : freedom of learning, education, character

\begin{abstract}
Abstrak
Merdeka belajar merupakan kebijakan pendidikan yang dicetuskan pada tahun 2019. Pendidikan merdeka belajar tidak lepas dari ikatan nilai-nilai karakter. Sekalipun kebijakan merdeka belajar mampu menghasilkan beberapa aturan terbaru di dunia pendidikan, namun implementasi nilainilai karakter sebagai wujud sumber daya manusia yang berbudi luhur tidak bisa dihapuskan. Implementasi nilai-nilai karakter tersebut dapat diterapkan dalam proses kegiatan belajar mengajar di sekolah. Nilai karakter yang diterapkan dalam pembelajaran merdeka belajar antara lain: (1) beriman, bertakwa kepada Tuhan Yang Maha Esa, dan berakhlak mulia, (2) berkebhinnekaan global, (3) bergotong royong, (4) mandiri, (5) bernalar kritis, (6) kreatif. Seluruh nilai-nilai tersebut bisa diterapkan di dalam kegiatan belajar mengajar di sekolah.
\end{abstract}

Kata kunci : merdeka belajar, pendidikan, karakter 


\section{PENDAHULUAN}

Pendidikan memiliki peranan penting untuk memenuhi sumber daya manusia yang jumlah dan mutunya memadai sebagai pendukung pembangunan. Hal ini sesuai dengan Undang-undang Nomor 20 Tahun 2003 tentang Sistem Pendidikan Nasional yang menyatakan bahwa pendidikan nasional bertujuan untuk mengembangkan potensi peserta didik agar menjadi manusia beriman dan bertakwa kepada Tuhan Yang Maha Esa, berakhlak mulia, sehat, berilmu, cakap, kreatif, mandiri, dan menjadi warga negara yang demokratis serta bertanggung jawab.

Kenyataannya keadaan yang digambarkan pada tujuan pendidikan nasional tersebut belum terwujud. Moral bangsa semakin merosot seiring dengan perkembangan waktu. Nilai-nilai yang ada sudah mulai terkikis dan hilang. Berbagai bentuk keadaan yang tidak diharapkan bermunculan di dalam kehidupan bermasyarakat. Keadaan tersebut ada yang berupa pelanggaran-pelanggaran terhadap aturan pemerintah maupun agama, kebebasan yang tidak diiringi tanggung jawab dan sebagainya. Seolaholah masyarakat sudah tidak takut lagi dengan adanya sanksi ataupun ikatan lainnya.

Merosotnya moral bangsa merupakan salah satu indikasi hancurnya bangsa tersebut. Oleh sebab itu, pembinaan karakter bangsa diupayakan guna menjadikan karakter yang baik sebagai pondasi bangsa. Individu yang berkarakter baik atau unggul merupakan seseorang yang berusaha melakukan hal-hal yang terbaik terhadap Tuhan Yang Maha Esa, dirinya, sesama lingkungan, bangsa dan bernegara serta dunia internasional pada umumnya. Hal tersebut terlaksana dengan mengoptimalkan potensi (pengetahuan) dirinya yang disertai dengan kesadaran, emosi dan motivasinya.

Pasca pelantikan Menteri Pendidikan dan Kebudayaan (Mendikbud), Nadiem Anwar Makarim, menyampaikan terobosan kebijakan pendidikan yang beliau sebut dengan istilah "Merdeka Belajar". (Kompas, 11/12/2019). Pokok-pokok kebijakan merdeka belajar meliputi empat program pendidikan yang menjadi fokus kebijakannnya, diantaranya: Ujian Sekolah Berstandar Nasional (USBN), Ujian Nassional (UN), Rencana Pelaksanaan Pembelajaran (RPP), dan Peraturan Penerimaan Peserta Didik Baru (PPDB) Zonasi.

Dalam kaitannya dengan merdeka belajar yang dicanangkan oleh Mendikbud, memahaminya dalam sudut pandang pendidikan karakter adalah penting. Terlebih arah kebijakan baru Mendikbud yang rencananya pada tahun 2021, UN akan diubah menjadi asesmen kompetensi minimum dan survei karakter. Pada kegiatan tanya jawab terkait kebijakan UN, Mendikbud menjelasan akan melakukan survei untuk mengukur aspekaspek lain yang mencerminkan penerapan Pancasila di sekolah. Hal ini mencakup aspek-aspek karakter siswa (seperti karakter pembelajar dan karakter gotong royong) dan iklim sekolah (misalnya iklim kebinekaan, perilaku bullying, dan kualitas pembelajaran).

Dengan memahami dan menerapkan nilai-nilai pendidikan karakter dan dihubungkan dengan gebrakan kebijakan merdeka belajar yang telah dicanangkan oleh Mendikbud, diharapkan membawa dampak kemajuan terhadap pendidikan di Indonesia dalam upaya penguatan pendidikan karakter dengan prinsip dan arah dan tujuan yang jelas. Selain itu, pendidikan di Indonesia menjadi lebih berkualitas sesuai harapan masyarakat Indonesia sebagaimana yang telah diamanatkan oleh UUD 1945.

\section{HASIL DAN PEMBAHASAN}

\section{Pendidikan Karakter}

Secara etimologi, kata karakter atau dalam bahasa Inggris disebut "character" berasal dari kata Yunani "charassein" dalam Webster's New World Dictionary of the American Language yang berarti "to engrave". Kata "to engrave" bisa diterjemahkan 
mengukir, melukis, memahatkan, atau menggoreskan (Echols dan Shadily, 1992:214). Menurut Kamus Besar Bahasa Indonesia, karakter merupakan sifat kejiwaan, akhlak atau budi pekerti yang membedakan seseorang dengan yang lain (Pusat Bahasa Depdiknas, 2008:623).

Prayitno (2011:15) menyebutkan bahwa karakter adalah sifat pribadi yang relatif stabil pada diri individu yang menjadi landasan bagi penampilan perilaku dalam standar nilai dan norma yang tinggi. Menurut Koesoema (2007:80) orang berkarakter berarti orang yang berkepribadian, berperilaku, bersifat, bertabiat, atau berwatak. Dengan makna tersebut berarti karakter identik dengan kepribadian atau akhlak. Kepribadian merupakan ciri atau karakteristik sifat khas dari diri seseorang yang bersumber dari bentukan-bentukan yang diterima dari lingkungan, misalnya keluarga pada masa kecil, dan juga bawaan sejak lahir.

Menurut Lickona (2013:75) karakter tersusun dari tiga bagian yang saling berhubungan yakni pengetahuan moral, perasaan moral, perilaku moral. Karakter yang baik terdiri dari pengetahuan tentang kebaikan (knowing the good), keinginan terhadap kebaikan (desiring the good), dan berbuat kebaikan (doing the good).

Dari pengertian di atas dapat dipahami bahwa karakter identik dengan akhlak berupa nilai-nilai perilaku dan aktivitas manusia yang universal, baik dalam rangka hubungan dengan Tuhannya, dengan dirinya sendiri, dengan sesama manusia, maupun dengan lingkungannya, yang terwujud dalam pikiran, sikap, perasaan, perkataan, dan perbuatan berdasarkan norma-norma agama.

\section{Nilai-Nilai Pendidikan Karakter}

Dalam pendidikan budaya dan karakter bangsa, nilai-nilai yang dikembangkan diidentifikasi dari empat sumber yakni, agama, Pancasila, budaya dan tujuan pendidikan nasional (Sulistyowati, 2012:28). Sumber pertama dari sisi agama melihat masyarakat Indonesia adalah masyarakat beragama. Oleh karena itu kehidupan individu, masyarakat, bangsa dan negara selalu didasarkan pada agama dan kepercayaannya.

Sumber kedua yakni Pancasila, Negara Kesatuan Republik Indonesia (NKRI) ditegakkan atas prinsip-prinsip kehidupan kebangsaan dan kenegaraan yakni Pancasila. Pancasila terdapat dalam Pembukaan UUD 1945 dan dijabarkan lebih lanjut dalam pasal-pasal yang terdapat dalam UUD 1945. Artinya nilai-nilai yang terkandung di dalam Pancasila menjadi salah satu nilai-nilai yang mengatur kehidupan politik, hukum, ekonomi, masyarakat, budaya dan seni.

Sumber ketiga dari sisi budaya, dapat diketahui bahwa budaya sebagai suatu kebenaran. Tidak ada manusia yang hidup bermasyarakat yang tidak didasari oleh nilainilai budaya yang diakui masyarakat tersebut. Nilai-nilai budaya tersebut dijadikan dasar dalam pemberian makna terhadap suatu konsep dan arti dalam komunikasi antar anggota masyarakat. Dengan demikian budaya sangat penting dalam posisi kehidupan bermasyarakat. Budaya menjadi sumber nilai dalam pendidikan karakter bangsa.

Sumber keempat adalah tujuan pendidikan nasional. Tujuan pendidikan nasional memuat berbagai nilai kemanusiaan yang harus dimiliki oleh warga negara Indonesia. Oleh karena itu, tujuan pendidikan nasional adalah sumber yang paling operasional dalam pengembangan pendidikan budaya dan karakter bangsa.

Berdasarkan keempat sumber tersebut, teridentifikasi 18 nilai yang dapat dikembangkan melalui pendidikan karakter bangsa yang bersumber dari agama, Pancasila, budaya dan tujuan pendidikan nasional (Kemendiknas, 2010: 9-10) nilai-nilai itu tersebut adalah sebagai berikut.

1. Religius

Sikap dan perilaku yang patuh dalam melaksanakan ajaran agama yang dianutnya, toleran terhadap pelaksanaan ibadah agama lain, dan hidup rukun dengan pemeluk agama lain.

2. Jujur

Perilaku yang didasarkan pada perilaku yang menjadikan dirinya sebagai orang yang selalu dapat dipercaya dalam perkataan, tindakan dan pekerjaan baik 


\section{SHEs: Conference Series 3 (2) (2020) 353- 363}

terhadap diri dan pihak lain.

3. Toleransi

Sikap dan tindakan yang menghargai perbedaan agama, suku, etnis, pendapat, sikap, dan tindakan orang lain yang berbeda dengan dirinya.

4. Disiplin

Tindakan yang menunjukkan perilaku tertib dan patuh pada berbagai ketentuan dan peraturan.

5. Kerja Keras

Perilaku yang menunjukkan perilaku sungguh-sungguh dalam mengatasi berbagai hambatan belajar dan tugas serta menyelesaikan tugas dengan sebaik-baiknya.

6. Kreatif

Berpikir dan melakukan sesuatu untuk menghasilkan cara atau hasil baru dari sesuatu yang dimiliki.

7. Mandiri

Sikap dan perilaku yang tidak mudah bergantung pada orang lain dalam menyelesaikan tugas-tugas.

8. Demokratis

Cara berpikir bersikap dan bertindak yang menilai sama hak dan kewajiban dirinya dengan orang lain.

9. Rasa Ingin Tahu

Sikap dan tindakan yang selalu berupa untuk mengetahui lebih mendalam dan meluas dari sesuatu yang dipelajarinya, dilihat dan didengar.

10. Semangat Kebangsaan

Cara berpikir, bertindak dan berwawasan yang menempatkan kepentingan bangsa dan negara di atas kepentingan diri sendiri dan golongannya.

11. Cinta Tanah Air

Cara berpikir, bersikap, dan berbuat yang menunjukkan kesetiaan, kepedulian, dan penghargaan yang tinggi terhadap bahasa, lingkungan fisik, sosial, budaya, ekonomi, politik dan bangsa.

12. Menghargai Prestasi

Sikap dan tindakan yang mendorong dirinya untuk menghasilkan sesuatu yang berguna bagi masyarakat dan mengakui serta menghormati keberhasilan orang lain.

13. Bersahabat atau Komunikatif

Tindakan yang memperlihatkan rasa senang berbicara, bergaul, dan bekerja sama dengan orang lain.

14. Cinta Damai

Sikap, perkataan dan tindakan yang menyebabkan orang lain merasa senang dan aman dengan kedatangan dirinya.

15. Gemar Membaca

Kebiasaan menyediakan waktu untuk membaca berbagai bacaan yang memberikan kebajikan pada dirinya.

16. Peduli Lingkungan

Sikap dan tindakan yang selalu berupaya mencegah kerusakan pada lingkungan sekitar dan mengembangkan upaya-upaya untuk memperbaiki kerusakan alam yang sudah terjadi.

17. Peduli Sosial

Sikap dan tindakan yang selalu ingin memberi bantuan pada orang lain dan masyarakat yang membutuhkan.

18. Tanggung Jawab

Sikap dan perilaku seseorang untuk melaksanakan tugas dan kewajibannya yang seharusnya dia lakukan terhadap diri sendiri, masyarakat lingkungan (alam, sosial, budaya, negara dan Tuhan).

Dengan demikian dapat dijabarkan bahwa dalam pendidikan karakter telah teridentifikasi 
nilai yang bersumber dari agama, Pancasila, budaya dan tujuan pendidikan nasional, yaitu : religius, jujur, toleransi, disiplin, kerja keras, kreatif, mandiri, demokratis, rasa ingin tahu, semangat kebangsaan, cinta tanah air, menghargai prestasi, bersahabat dan komunikatif, cinta damai, gemar membaca, peduli lingkungan, peduli sosial, dan tanggung jawab.

\section{Etimologi Merdeka Belajar}

Menurut Wikipedia, secara etimologi kata merdeka berasal dari bahasa Sanskerta "maharddhika" yang berarti kaya, sejahtera dan kuat. Lain halnya kata merdeka dalam bangsa Belanda berakar dari kata "mardijker" sebagai kata yang diturunkan secara tidak tepat dari versi bahasa Portugis dari kata asli yang jugaberasal dalam bahasa Sanskerta yakni maharddhika. Kata ini digunakan oleh penjajah Portugis dan Belanda untuk menunjuk mantan budak dari India di Hindia Belanda.

De Mardijkers atau kaum mardiker adalah sebutan umum abad XVII-XVIII untuk para bekas budak dari Asia atau Afrika yang telah dimerdekakan, dan kemudian bersama keturunannya mengikuti budaya penjajahnya. Dalam arti sempit, kaum mardiker merujuk pada sekelompok bekas tawanan perang yang diperoleh Belanda (VOC) hasil kemenangannya menduduki wilayah jajahan Portugis di Asia (India, Melaka), yang kemudian dibawa ke Batavia dan dimerdekakan setelah memenuhi syarat tertentu. Di Jakarta, keturunan kaum mardiker ini masih tersisa, di antaranya di Kampung Tugu, wilayah Jakarta Utara. Kelompok ini juga dikenal dengan sebutan Portugis Hitam. (Wikipedia).

Kata merdeka dari Indonesia sendiri adalah kata dalam bahasa Melayu yang bermakna bebas atau tidak bergantung/independen. Jika difusikan kata 'merdeka' dan 'belajar' yang disebut dengan "merdeka belajar" dapat diartikulasikan kemerdekaan untuk melahirkan tatanan masyarakat yang berkhidmat dan bijaksana dalam mencapai potensi maksimal manusia sebagai manusia Indonesia. Semua idealitas merdeka belajar tetap diwadahi dalam sebuah proses belajar menjadi manusia yang merdeka, sehingga merdeka belajar menjadi sebuah proses belajar manusia Indonesia yang merdeka.

\section{Merdeka Belajar dalam Perspektif Pendidikan Karakter}

Merdeka belajar merupakan kemerdekaan berpikir. Konsep ini merupakan respons terhadap kebutuhan sistem pendidikan dalam telaah metode pembelajaran dan sistem pengajarannya pada era Revolusi Industri 4.0.

Gebrakan kebijakan merdeka belajar yang dicetuskan pemerintah bukan tanpa alasan. Pasalnya, penelitian Programme for International Student Assesment (PISA) tahun 2019 menunjukkan hasil penilaian pada peserta didik Indonesia hanya menduduki posisi keenam dari bawah; untuk bidang matematika dan literasi, Indonesia menduduki posisi ke-74 dari 79 Negara. Menyikapi hal itu, Nadiem sebagai Menteri Pendidikan pun membuat gebrakan penilaian dalam kemampuan minimum, meliputi literasi, numerasi, dan survei karakter. Literasi bukan hanya mengukur kemampuan membaca, tetapi juga kemampuan menganalisis isi bacaan beserta memahami konsep di baliknya. Untuk kemampuan numerasi, yang dinilai bukan pelajaran matematika, tetapi penilaian terhadap kemampuan peserta didik dalam menerapkan konsep numerik dalam kehidupan nyata. Satu aspek sisanya, yakni survei karakter, bukanlah sebuah tes, melainkan pencarian sejauh mana penerapan nilai-nilai budi pekerti, agama, dan Pancasila yang telah dipraktekkan oleh peserta didik. (Mustaghfiroh, 2020:145).

Mendikbub, Nadiem Anwar Makarim, pernah menjabarkan enam Profil Pelajar Pancasila, yakni: (1) beriman, bertakwa kepada Tuhan Yang Maha Esa, dan berakhlak mulia, (2) berkebhinnekaan global, (3) bergotong royong, (4) mandiri, (5) bernalar kritis, (6) kreatif. Tentu dengan enam Profil Pelajar Pancasila ini adalah sangat relevan untuk di interpretasikan sebagai nilai-nilai pendidikan karakter di era merdeka belajar. 
Dalam sebuah acara seminar nasional dalam jaringan yang diselenggarakan Program Studi S2 Pendidikan Sejarah, Universitas Sebelas Maret (29/08/2020), Nunuk Suryani memberikan penjelasan enam Profil Pelajar Pancasila sebagai berikut :

1. Beriman, bertakwa kepada Tuhan Yang Maha Esa, dan berakhlak mulia Memahami moralitas, spiritualitas, dan etika beradab, yang merupakan hasil dari pendidikan karakter.

Pelajar Indonesia yang beriman, bertakwa kepada Tuhan YME, dan berakhlak mulia adalah pelajar yang berakhlak dalam hubungannya dengan Tuhan Yang Maha Esa. la memahami ajaran agama dan kepercayaannya serta menerapkan pemahaman tersebut dalam kehidupannya sehari-hari. Ada lima elemen kunci beriman, bertakwa kepada Tuhan YME, dan berakhlak mulia: (a) akhlak beragama; (b) akhlak pribadi; (c) akhlak kepada manusia; (d) akhlak kepada alam; dan (e) akhlak bernegara.

2. Berkebhinnekaan global

Mencintai keberagaman budaya, agama dan ras di negaranya serta dunia, sekaligus menegaskan mereka juga warga global.

Pelajar Indonesia mempertahankan budaya luhur, lokalitas dan identitasnya, dan tetap berpikiran terbuka dalam berinteraksi dengan budaya lain, sehingga menumbuhkan rasa saling menghargai dan kemungkinan terbentuknya budaya baru yang positif dan tidak bertentangan dengan budaya luhur bangsa. Elemen kunci dari berkebinekaan global meliputi mengenal dan menghargai budaya, kemampuan komunikasi interkultural dalam berinteraksi dengan sesama, dan refleksi dan tanggung jawab terhadap pengalaman kebinekaan.

3. Bergotong royong

Memiliki kemampuan berkolaborasi agar bisa bekerja secara tim.

Pelajar Indonesia memiliki kemampuan bergotong royong, yaitu kemampuan untuk melakukan kegiatan secara bersama-sama dengan suka rela agar kegiatan yang dikerjakan dapat berjalan lancar, mudah dan ringan. Elemen-elemen daribergotong royong adalah kolaborasi, kepedulian, dan berbagi.

4. Mandiri

Secara independen termotivasi meningkatkan kemampuannya.

Pelajar Indonesia merupakan pelajar mandiri, yaitu pelajar yang bertanggung jawab atas proses dan hasil belajarnya. Elemen kunci dari mandiri terdiri dari kesadaran akan diri dan situasi yang dihadapi serta regulasi diri.

5. Bernalar kritis

Memiliki kemampuan memecahkan masalah

Pelajar yang bernalar kritis mampu secara objektif memproses informasi baik kualitatif maupun kuantitatif, membangun antara berbagai informasi, menganalisis informasi, mengevaluasi dan menyimpulkannya. elemen-elemen dari bernalar kritis

adalah memperoleh dan memproses informasi dan gagasan, menganalisis dan mengevaluasi penalaran, merefleksi pemikiran dan proses berpikir, dan mengambil keputusan.

6. Kreatif

Menciptakan hal baru, berinovasi secara mandiri, dan mempunyai rasa cinta terhadap kesenian dan budaya.

Pelajar yang kreatif mampu memodifikasi dan menghasilkan sesuatu yang orisinal, bermakna, bermanfaat, dan berdampak. Elemen kunci dari kreatif terdiri dari menghasilkan gagasan yang orisinal serta menghasilkan karya dan tindakan yang orisinal. 
Keenam karakteristik Profil Pelajar Pancasila ini terwujud melalui penumbuhkembangan nilai-nilai budaya Indonesia dan Pancasila, yang adalah fondasi bagi segala arahan pembangunan nasional. Dengan identitas budaya Indonesia dan nilai-nilai Pancasila yang berakar dalam masyarakat Indonesia ke depan akan menjadi masyarakat terbuka yang berkewargaan global, dapat menerima dan memanfaatkan keragaman sumber, pengalaman, serta nilai-nilai dari beragam budaya yang ada di dunia, namun sekaligus tidak kehilangan ciri dan identitas khasnya. (Nunuk Suryani dalam seminar nasional dalam jaringan, 2019:10-15).

Melalui enam Profil Pelajar Pancasila ini dapat dikembangkan sejalan dengan nilai-nilai pendidikan karakter melalui empat cara sebagai berikut:

\section{Tabel 1. Profil Pelajar Pancasila yang dikembangkan sejalan dengan nilai-nilai pendidikan karakter}

1. Melalui pembiasaan

\begin{tabular}{|c|c|c|}
\hline No & Profil Pelajar Pancasila & Bentuk Kegiatan \\
\hline 1. & $\begin{array}{l}\text { Beriman, bertakwa } \\
\text { kepada Tuhan Yang Maha } \\
\text { Esa, dan berakhlak mulia }\end{array}$ & $\begin{array}{l}\text { - Guru dan siswa berdoa bersama sebelum dan } \\
\text { sesudah pembelajaran } \\
\text { - Melaksanakan ibadah sesuai agama dan } \\
\text { kepercayaannya } \\
\text { - Perayaan hari keagamaan dengan kegiatan } \\
\text { yang sederhana dan hidmat }\end{array}$ \\
\hline 2. & Kebhinnekaan global & $\begin{array}{l}\text { - Melaksanakan upacara bendera tiap hari senin } \\
\text { - } \\
\text { Menyanyikan lagu bernuansa patriotik dan cinta } \\
\text { - } \text { Mengenalkan beragam keunikan potensi } \\
\text { daerah } \\
\text { - Menguasai bahasa asing untuk mempelajari } \\
\text { ilmu pengetahuan } \\
\text { - Memberlakukan segala peraturan } \\
\text { pembelajaran tanpa membedakan suku } \\
\text { maupun agama tertentu kepada } \\
\text { - Memperkenalkan kebudayaan daerah kepan } \\
\text { siswa } \\
\text { - Memperkenalkan beragam tempat wisata } \\
\text { daerah Indonesia kepada siswa }\end{array}$ \\
\hline \multirow[t]{2}{*}{3.} & Bergotong royong & 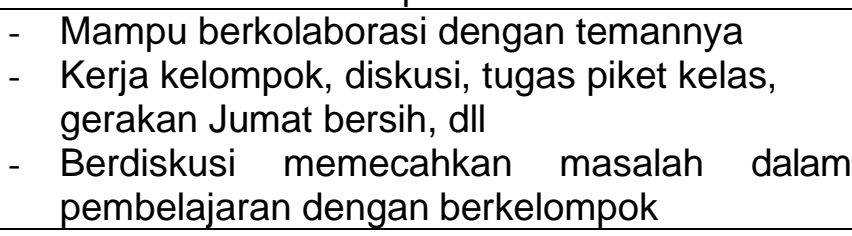 \\
\hline & & $\begin{array}{l}\text { - Saling membantu berbagi informasi penting } \\
\text { khususnya di bidang akademik oleh siswa } \\
\text { - Guru memberikan kesempatan kepada siswa } \\
\text { untuk membentuk kelompok belajar di luar } \\
\text { kelas }\end{array}$ \\
\hline
\end{tabular}




\begin{tabular}{|c|c|c|}
\hline 4. & Mandiri & $\begin{array}{l}\text { - } \text { Mengunjungi perpustakaan untuk mencari ilmu } \\
\text { - } \text { Mecara mandiri } \\
\text { - } \text { Pemberjakan tugas-tugas dari guru } \\
\text { - } \text { Siswa diperintahkan untuk mengerjakan tugas } \\
\text { sekolah maupun tugas rumah secara mandiri } \\
\text { - Guru mengarahkan siswa untuk tidak } \\
\text { bergantung pada kunci jawaban setiap kali } \\
\text { mengerjakan soal atau latihan } \\
\text { - Siswa mempersiapkan segala peralatan } \\
\text { belajarnya dengan mandiri }\end{array}$ \\
\hline 5. & Bernalar kritis & $\begin{array}{l}\text { - Membaca menulis, diskusi, bedah buku, } \\
\text { melaporkan hasil membaca } \\
\text { - Membiasakan siswa mengemukakan pendapat } \\
\text { di dalam kelas } \\
\text { - Melatih siswa memberi argumen terhadap } \\
\text { persoalan tertentu dengan mengandalkan data } \\
\text { atau konsep teoritis } \\
\text { - Melatih siswa memecahkan masalah dengan } \\
\text { memberikan argumen yang tepat dan sesuai } \\
\text { konsep }\end{array}$ \\
\hline 6. & Kreatif & $\begin{array}{l}\text { - Menyanyikan lagu Indonesia Raya } \\
\text { - } \text { Menyanyikan lagu daerah } \\
\text { - Melatih siswa melaksanakan tugas dengan } \\
\text { kreativitas masing-masing sesuai dengan } \\
\text { penilaian tugas }\end{array}$ \\
\hline
\end{tabular}

2. Melalui pembinaan siswa

\begin{tabular}{|c|c|c|}
\hline No & Profil Pelajar Pancasila & Bentuk Kegiatan \\
\hline 1. & $\begin{array}{l}\text { Beriman, } \quad \text { bertakwa } \\
\text { kepada Tuhan Yang Maha } \\
\text { Esa, dan berakhlak mulia }\end{array}$ & $\begin{array}{ll} & \text { Pembinaan keimanan dan ketakwaan terhadap } \\
& \text { Tuhan YME melalui ekstrakurikuler } \\
\text { - } & \text { Masa pengenalan lingkungan sekolah } \\
\text { - } & \text { Tata krama dan tata tertib sekolah } \\
\text { - } & \text { Pencegahan penyalahgunaan narkoba }\end{array}$ \\
\hline 2. & Kebhinnekaan global & $\begin{array}{l}\text { - } \begin{array}{l}\text { Mengadakan pentas seni dari berbagai daerah } \\
\text { - }\end{array} \text { Festival pakaian adat dari berbagai suku } \\
\text { bangsa } \\
\text { - Penguasaan bahasa asing sebagai media } \\
\text { untuk melakukan pergaulan global }\end{array}$ \\
\hline 3. & Bergotong royong & $\begin{array}{ll}- & \text { Melaksanakan kerja bakti (bakti sosial) } \\
- & \text { Jumat peduli para orang miskin } \\
- & \text { Musyawarah mufakat } \\
- & \text { Ikut terlibat dalam setiap kegiatan di sekolah }\end{array}$ \\
\hline 4. & Mandiri & $\begin{array}{l}\text { - Melaksanakan ekstrakurikuler pramuka dan } \\
\text { OSIS } \\
\text { - Kegiatan para pelajar peduli lingkungan }\end{array}$ \\
\hline
\end{tabular}




\begin{tabular}{|c|c|c|}
\hline 5. & Bernalar kritis & $\begin{array}{ll}\text { - } & \text { Kegiatan membaca masal (readathon) } \\
\text { - } & \text { Pemilihan duta literasi } \\
\text { - } & \text { Kelompok ilmiah remaja } \\
\text { - } & \text { Mengikuti lomba penelitian siswa nasional }\end{array}$ \\
\hline 6. & Kreatif & $\begin{array}{ll}\text { - } & \text { Pembinaan bakat minat pada kegiatan } \\
& \text { ekstrakurikuler (sain, olahraga, seni, bahasa) } \\
\text { - } & \text { Expo hasil karya siswa } \\
\text { - } & \text { Menyelenggarakan OBSI SIOLGA (olimpiade } \\
& \text { sain, bahasa Indonesia, seni, dan olahraqa) }\end{array}$ \\
\hline
\end{tabular}

3. Melalui pembelajaran

\begin{tabular}{|c|c|c|c|}
\hline No & $\begin{array}{l}\text { Profil Pelajar } \\
\text { Pancasila }\end{array}$ & $\begin{array}{l}\text { Mata Pelajaran yang } \\
\text { Diintegrasikan }\end{array}$ & Bentuk Kegiatan \\
\hline 1. & 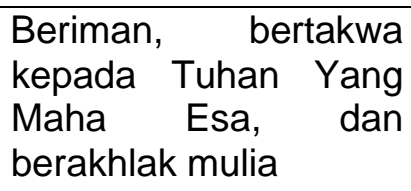 & Semua mata pelajaran & $\begin{array}{ll}\text { - } & \text { Berdoa sebelum dan } \\
& \text { sesudah belajar } \\
\text { - } & \text { Pengenalan nilai-nilai imtak } \\
& \text { pada semua mata pelajaran }\end{array}$ \\
\hline 2. & Kebhinnekaan global & $\begin{array}{l}\text { - Bahasa Inggris } \\
\text { - IPS (sejarah) }\end{array}$ & $\begin{array}{ll}\text { - } & \text { Penguasaan bahasa Inggris } \\
\text { - } & \text { Memahami budaya } \\
& \text { nasional, global }\end{array}$ \\
\hline 3. & Bergotong royong & Semua mata pelajaran & $\begin{array}{ll}\text { - } & \text { Kerja kelompok } \\
\text { - } & \text { Berdiskusi }\end{array}$ \\
\hline 4. & Mandiri & Semua mata pelajaran & $\begin{array}{ll}\text { - } & \text { Pembelajaran jarak jauh } \\
\text { melalui daring di masa } \\
\text { Covid-19 } \\
\text { - } \text { Mengerjakan semua tugas- } \\
\text { tugas dari semua guru mata } \\
\text { pelajaran }\end{array}$ \\
\hline 5. & Bernalar kritis & Semua mata pelajaran & $\begin{array}{l}\text { - Semua siswa membaca } \\
\text { buku teks, buku penunjang, } \\
\text { dan sumber belajar lainnya } \\
\text { untuk melatih berpikir kritis } \\
\text { dalam menyikapi fenomena } \\
\text { kehidupan di masyarakat }\end{array}$ \\
\hline 6. & Kreatif & Semua mata pelajaran & 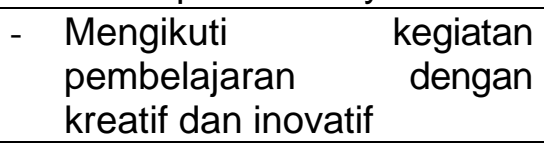 \\
\hline
\end{tabular}

4. Melalui manajemen sekolah

Prinsip manajemen sekolah dalam pengembangan Pancasila yakni :

1) Kejelasan tugas dan pertanggungjawaban

2) Pembagian kerja berdasarkan keahliannya

3) Kesatuan arah kebijakan

4) Teratur

5) Disiplin

6) Adil

7) Inisiatif

8) Semangat kebersamaan

9) Sinergis

10) Ikhlas (Budi Suhardiman, 2020:6-13) 
Yudi latif (2020: 310) menjelaskan bahwa pengembangan karakter adalah suatu pendekatan holistik yang menghubungkan dimensi moral pendidikan dengan ranah sosial dan sipil dari kehidupan peserta didik. Dalam konteks ini, penjejalan pengetahuan positif yang bersifat taken for granted bukanlah menjadi hal yang terpenting, melainkan bagaimana mengajarkan kepada peserta didik agar mampu mengembangkan kekuatan bernalar dan bermoral. Sebagai bentuk upaya yang dapat dilakukan adalah dengan memberikan kemerdekaan kepada peserta didik untuk melibatkan diri secara langsung dalam kegiatan proses belajar mengajar dan transfer keilmuan. Peserta didik bukan hanya sekadar objek pendidikan melainkan dianggap sebagai subjek utama dari sebuah proses pendidikan dan semua peserta didik adalah faktor yang diperhitungakan secara keseluruhan, saling bergantung sama lain untuk kepentingan semua.

\section{SIMPULAN}

Merdeka belajar merupakan program pembelajaran yang membebaskan individu untuk memperoleh dan berbagi individu di dalam pendidikan. Guru dituntut untuk lebih membangkitkan nilai-nilai Pancasila sebagai kunci karakter dalam pendidikan. Implementasi nilai-nilai Pancasila dapat dilaksanakan melalui kegiatan belajar mengajar. Dengan demikian tujuan pembelajaran nasional menjadikan manusia Indonesia cerdas dan berkarakter dapat terwujud.

\section{DAFTAR PUSTAKA}

Kemendikbud. Daftar Tanya Jawab Kebijakan Ujian Sekolah Berstandar Nasional (USBN), Retrieved from www.kemdikbud.go.id, on 27th Aug 2020.

Kemendiknas. 2010. Pengembangan Pendidikan Budaya dan Karakter Bangsa. Jakarta : Badan Penelitian dan Pengembangan Pusat Kurikulum.

Koesoema, A. Doni. 2007. Pendidikan Karakter. Jakarta : Gramedia.

Kompas. 2019. Terobosan Merdeka Belajar Nadiem Makarim, Ubah Sistem Zonasi hingga Hapus UN, Retrieved from www.kompas.com/tren/read/2019/12/12/082505665/terobosan-merdekabelajar-nadiem-makarim-ubah-sistem-zonasi-hingga-hapus-un?page=all, on 27th Aug 2020.

Latif, Yudi. 2020. Wawasan Pancasila: Bintang Penuntun untuk Pembudayaan edisi komprehensif. Jakarta : Mizan.

Lickona, Thomas. 2013. Pendidikan Karakter Panduan Lengkap Mendidik Siswa Menjadi Pintar dan Baik. Bandung : Nusa Media.

Pusat Bahasa Departemen Pendidikan Nasional. 2008. Kamus Bahasa Indonesia Cet. IV. Jakarta : Pusat Bahasa.

Prayitno. 2011. Model Pendidikan Karakter Cerdas. Padang : UNP Press.

Sulistyowati, Endah. 2012. Implementasi Kurikulum Pendidikan Karakter. Yogyakarta : Citra Aji Pramana. 
Siti Mustaghfiroh. 2020. “Konsep 'Merdeka Belajar' Perspektif Aliran Progresivisme John Dewey". Jurnal Studi Guru dan Pembelajaran, (3) (1) 141-147.

Suhardiman, Budi. 2020. Kepala Sekolah dan Pengembangan Profile Pelajar Pancasila, Disampaikan pada Kegiatan Seminar Nasional (dalam jaringan) Guru Belajar, Dirjen GTK, Kemdikbud Republik Indonesia, Jakarta.

Suryani, Nunuk. 2020. Kebijakan Merdeka Belajar dan Implementasi Nilai-Nilai Pancasila pada Era Tatanan Baru, Disampaikan pada Kegiatan Seminar Nasional (dalam jaringan) Pengamalan Nilai-nilai Pancasila dalam Pembelajaran Sejarah di Era Merdeka Belajar, Universitas Sebelas Maret, Solo.

Wikipedia. Mardijkers, Retrieved from id.m.wikipedia.org/wiki/Mardijkers, on 27th Aug 2020 